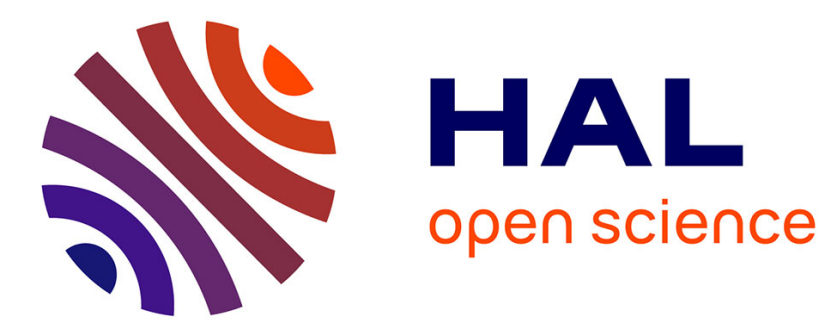

\title{
How Serious is the Measurement-Error Problem in a Popular Risk-Aversion Task?
}

Fabien Perez, Guillaume Hollard, Radu Vranceanu, Delphine Dubart

\section{To cite this version:}

Fabien Perez, Guillaume Hollard, Radu Vranceanu, Delphine Dubart. How Serious is the Measurement-Error Problem in a Popular Risk-Aversion Task?. 2019. hal-02291224

\section{HAL Id: hal-02291224 \\ https://essec.hal.science/hal-02291224}

Preprint submitted on 18 Sep 2019

HAL is a multi-disciplinary open access archive for the deposit and dissemination of scientific research documents, whether they are published or not. The documents may come from teaching and research institutions in France or abroad, or from public or private research centers.
L'archive ouverte pluridisciplinaire HAL, est destinée au dépôt et à la diffusion de documents scientifiques de niveau recherche, publiés ou non, émanant des établissements d'enseignement et de recherche français ou étrangers, des laboratoires publics ou privés. 


\section{ESSEC}

BUSINESS SCHOOL

\section{How Serious is the}

Measurement-Error Problem in

a Popular Risk-Aversion Task?

FABIEN PEREZ, GUILLAUME HOLLARD, RADU VRANCEANU, DELPHINE DUBART ESSEC RESEARCH CENTER

WORKING PAPER 1911

SEPTEMBER, 2019

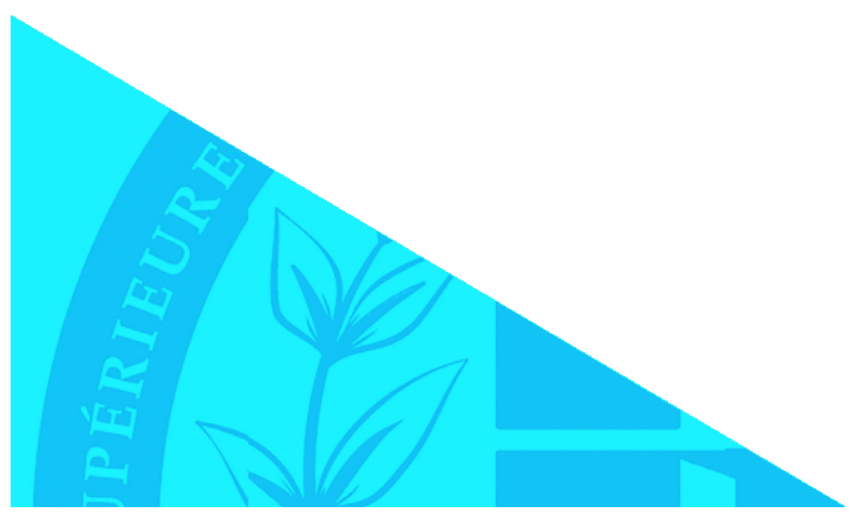




\title{
How Serious is the Measurement-Error Problem in a Popular
}

\section{Risk-Aversion Task?*}

\author{
Fabien Perez $†$ Guillaume Hollard $\ddagger$ Radu Vranceanu \\ Delphine Dubart
}

September 17, 2019

\begin{abstract}
This paper uses the test/retest data from the Holt and Laury (2002) experiment to provide estimates of the measurement error in this popular risk-aversion task. Maximumlikelihood estimation suggests that the variance of the measurement error is approximately equal to the variance of the number of safe choices. Simulations confirm that the coefficient on the risk measure in univariate OLS regressions is approximately half of its true value. Unlike measurement error, the discrete transformation of continuous riskaversion is not a major issue. We discuss the merits of a number of different solutions: increasing the number of observations, IV and the ORIV method developed by Gillen et al. (2019).
\end{abstract}

Keywords: Experiments; Measurement error; Risk-aversion, Test/retest; ORIV.

JEL Classification: C18; C26; C91; D81.

${ }^{*}$ The authors are grateful to Olivier Armantier, Gwen-Jiro Clochard, Paolo Crosetto, Jules Depersin, Antonio Filippin, Lucas Girard, Yannick Guyonvarch, Xavier d'Haultfoeuille, Nicolas Jacquemet and participants at the 10th International Conference of the ASFEE 2019 in Toulouse and the ESA European meeting 2019 in Dijon for their suggestions and remarks that helped to improve this work.

${ }^{\dagger}$ CREST, INSEE - 5 Avenue Le Chatelier, 91120 Palaiseau. E-mail: fabien.perez@ensae.fr.

${ }^{\ddagger}$ CREST, Ecole Polytechnique, CNRS - 5 Avenue Le Chatelier, 91120 Palaiseau. E-mail: guillaume.hollard@polytechnique.edu.

${ }^{\S}$ ESSEC Business School and THEMA, 1 Avenue Bernard Hirsch, 95021 Cergy. E-mail: vranceanu@essec.edu.

๑ESSEC Business School, 1 Avenue Bernard Hirsch, 95021 Cergy. E-mail: dubart@essec.edu. 


\section{Introduction}

Economists explain individual heterogeneity in observed behavior by appealing to a number of key individual characteristics, such as risk attitudes or time preferences. A common research practice is to elicit this kind of individual characteristic via an elementary task, and then use the resulting value as an explanatory variable in subsequent regressions. One example is the use of an elicitation method to measure risk attitudes, for example that proposed by Holt and Laury (2002), and then including the outcome from the task in some OLS regressions.

The potential issue here comes from the considerable within-individual variability in these elicited measures. For example, the correlations between different measures of risk attitudes for the same individual are typically small, even when the same task is repeated within a short period of time (see, for instance, the discussion and references in Bardsley et al. (2010)).

From an econometric perspective, within-individual variability can be interpreted as measurement error, which has well-known negative consequences: in OLS regressions, the coefficient on the explanatory variable measured with error is attenuated, and other variables that are actually not significant in multivariate regressions may wrongly be estimated to be so, as measurement error in one explanatory variable renders all of the estimates inconsistent.

Another difficulty comes from the fact that popular elicitation methods yield a discrete approximation of a continuous variable (e.g. risk-aversion or the discount rate). Rounding or truncating elicited measures will mechanically produce some imprecision. Last, estimated risk-aversion often comes from laboratory experiments with relatively small samples (e.g. $\mathrm{N}=100$ or 200). Many experimental-economics analyses then use small samples, with variables that are plagued by measurement error arising from intra-subject variability and rounding issues.

So far, little is known about the magnitude of this measurement error and rounding: What is the degree of attenuation of the coefficients in OLS regressions? How often will significant coefficients actually appear to be insignificant?

In this paper, we use test/retest information to gauge the size of the measurement error in the extremely popular Holt and Laury (2002) (HL) task to measure risk-aversion. 1 We here appeal to the relevant original information in Holt and Laury (2002), as they implemented a "return to baseline" task using the same group of participants in a standard test/retest

\footnotetext{
${ }^{1}$ In a relatively short period of time, this task has become the most popular risk-aversion elicitation method in experimental economics. as mentioned for instance in Zhou and Hey (2018), Charness et al. (2019), Attanasi et al. (2018), Crosetto and Filippin (2016). Google Scholar, accessed on 28.08.19, indicates 5400 citations for this paper.
} 
design. We can therefore compare the choices made by the same individual in the same task, repeated within a short period of time (in the same experimental session). As a robustness check, we carried out a test/retest of the HL task at the ESSEC Experimental Lab in 2019 (see Appendix A).

Our analysis proceeds in three steps. (1) we carry out maximum-likelihood (ML) joint estimations of the variance of the measurement error, as well as of the mean and variance of the variable of interest (the number of safe choices in the Holt-Laury task; see the next section for details). (2) We simulate a linear stochastic model and carry out a large number of univariate OLS regressions. We also vary the sample sizes (with $\mathrm{N}=100$ being the benchmark). This allows us to assess the respective impact of the measurement error and rounding on the variance and significance of the estimated coefficient. (3) Finally, we use the simulations to analyze and compare possible solutions to the measurement-error problem, such as increasing the number of observations, using IV estimators or the Obviously Related Instrumental Variables (ORIV) method developed by Gillen et al. (2019).

Two relevant contributions address the issue of measurement error in experimental data. Gillen et al. (2019) replicate three classic experiments using an original data set (the Caltech cohort survey), and show that the results can change dramatically when the measurement error is correctly accounted for. Our analysis here addresses two important elements not considered there: the impact of the sample size (in particular the small sample sizes typical of laboratory experiments) and the rounding issue arising from the use of a discrete measure of a continuous variable. Engel and Kirchakamp (2019) adopt an alternative method to estimate the measurement error in the HL task. Their focus is on inconsistent answers, 2 and they aim to estimate an individual-specific error term (while we here assume that the error terms are independent between tasks, and are drawn from the same distribution for all individuals). In contrast, we use test/retest data to evaluate the size of the measurement error. Test/retest is a simpler way of evaluating the importance of measurement error, and can be applied even when the number of inconsistent choices is small.

We find that:

(1) Assuming normal distributions, the maximum-likelihood (ML) estimated variance of the measurement error is close to 1 , similar to the variance of the latent risk-aversion variable. In theory, the attenuation factor is close to 0.5 , regardless of the size of the sample. Our subsequent simulations indeed indicate that the typical amount of noise in the HL task

\footnotetext{
2 Jacobson and Petrie (2009) record a large number of such mistakes in a different experiment, and argue that they can provide information about the true population distribution of the risk-aversion coefficient.
} 
will roughly divide the coefficient of interest by 2 .

(2) Our simulations also show that in this task the discrete transformation of the variable of interest (i.e. rounding) does not much affect the attenuation bias, and only marginally affects the variance of the estimators. By way of contrast, the measurement error arising from within-subject variability is responsible for much of the effect on the estimated coefficient.

(3) Increasing the sample size does not alleviate the attenuation bias, but does increase the significance of the estimated coefficient. Going up to $N=1000$ suffices for the coefficient to become significant almost $100 \%$ of the time, while smaller sample sizes (e.g. $N=100$ or $N=200)$ produce a large proportion of insignificant coefficients.

(4) As expected, the ORIV method almost completely removes the bias, although ORIV estimates have larger variances than the true OLS estimates. ORIV may not suffice to solve the significance issue resulting from measurement error for small samples.

(5) Using ORIV and increasing the sample size are powerful solutions to address the estimation biases induced by measurement error in the Holt and Laury task (and probably other tasks as well).

The remainder of the paper is organized as follows. The next section briefly describes the HL task and the data. Section 3 provides ML estimates for the variance of the measurement error, and the mean and variance of the variable of interest. Section 4 uses these parameters to simulate a linear stochastic model, and then carries out 100000 regressions under different assumptions about the properties of the explanatory variable. The last section concludes.

\section{The Holt and Laury (2002) task: A primer}

The Holt and Laury (2002) (HL) risk-aversion elicitation task consists in choosing between a "safe" (small-spread) lottery $\frac{x}{10} \cdot 2 \$+\left(1-\frac{x}{10}\right) \cdot 1 \cdot 6 \$$ and a "risky" (wide-spread) lottery $\frac{x}{10} \cdot 3.85 \$+\left(1-\frac{x}{10}\right) \cdot 0.10 \$$ for $x \in \llbracket 1,10 \rrbracket$. 
Table 1: The Holt and Laury (2002) risk-aversion elicitation task

\begin{tabular}{cc}
\hline \hline Option A & Option B \\
\hline $1 / 10$ of $\$ 2.00,9 / 10$ of $\$ 1.60$ & $1 / 10$ of $\$ 3.85,9 / 10$ of $\$ 0.10$ \\
$2 / 10$ of $\$ 2.00,8 / 10$ of $\$ 1.60$ & $2 / 10$ of $\$ 3.85,8 / 10$ of $\$ 0.10$ \\
$3 / 10$ of $\$ 2.00,7 / 10$ of $\$ 1.60$ & $3 / 10$ of $\$ 3.85,7 / 10$ of $\$ 0.10$ \\
$4 / 10$ of $\$ 2.00,6 / 10$ of $\$ 1.60$ & $4 / 10$ of $\$ 3.85,6 / 10$ of $\$ 0.10$ \\
$5 / 10$ of $\$ 2.00,5 / 10$ of $\$ 1.60$ & $5 / 10$ of $\$ 3.85,5 / 10$ of $\$ 0.10$ \\
$6 / 10$ of $\$ 2.00,4 / 10$ of $\$ 1.60$ & $6 / 10$ of $\$ 3.85,4 / 10$ of $\$ 0.10$ \\
$7 / 10$ of $\$ 2.00,3 / 10$ of $\$ 1.60$ & $7 / 10$ of $\$ 3.85,3 / 10$ of $\$ 0.10$ \\
$8 / 10$ of $\$ 2.00,2 / 10$ of $\$ 1.60$ & $8 / 10$ of $\$ 3.85,2 / 10$ of $\$ 0.10$ \\
$9 / 10$ of $\$ 2.00,1 / 10$ of $\$ 1.60$ & $9 / 10$ of $\$ 3.85,1 / 10$ of $\$ 0.10$ \\
$10 / 10$ of $\$ 2.00,0 / 10$ of $\$ 1.60$ & $10 / 10$ of $\$ 3.85,0 / 10$ of $\$ 0.10$ \\
\hline
\end{tabular}

The data set comes from the initial article by Holt and Laury (2002), who elicited the risk measure for their main treatment (Table 1) twice: once at the beginning of the experimental session and once at the end, after having subjects perform variants of the same task with higher stakes. Their sample included a total of 175 subjects from three US Universities; half were undergraduate students, one third MBA students and the rest business-faculty members. 目

Assuming that subjects maximize their expected utility, is twice-differentiable, the value $x^{*}$ (a continuous variable) for which the subject is indifferent between the safe and the risky lottery is strictly increasing in the coefficient of risk-aversion. $x^{*}$ is thus a valid variable to describe risk preferences, and is our variable of interest.

Subjects generally start by choosing the safe option when $x=1$ and shift to the risky option for a larger $x$, more precisely for $\left\lfloor x^{*}\right\rfloor+1$. The number of times the safe option chosen is therefore $\left\lfloor x^{*}\right\rfloor$. This discrete variable is the standard measure of risk-aversion recommended by Holt and Laury (2002). 目 Using a discrete transformation to approximate a continuous variable introduces some imprecision.

In the scatter diagram in Figure 1, the horizontal axis represents the number of times an individual chose the safe option in the first test, and the vertical axis the same number

\footnotetext{
${ }^{3} \mathrm{We}$ manually transcribed the data provided at the address http://www.people.virginia.edu / cah2k/highdata.pdf.

${ }^{4}$ The debates around this standard decision model are beyond the scope of the current paper; see O'Donoghue and Somerville (2018) for a recent discussion.

${ }^{5} \mathrm{On}$ average subjects choose the safe option six times out of ten.
} 
in the last (retest) test at the end of the session. The size of the circles reflects the number of individuals making a given choice. The dispersion of the circles suggests that noise other than discretization affects the risk-aversion measures. The observed variables with noise and discrete transformation can be written as: $x_{1}=\left\lfloor x^{*}+\epsilon_{1}\right\rfloor$ and $x_{2}=\left\lfloor x^{*}+\epsilon_{2}\right\rfloor$, where $\epsilon_{1}$ and $\epsilon_{2}$ are the noise or measurement errors.

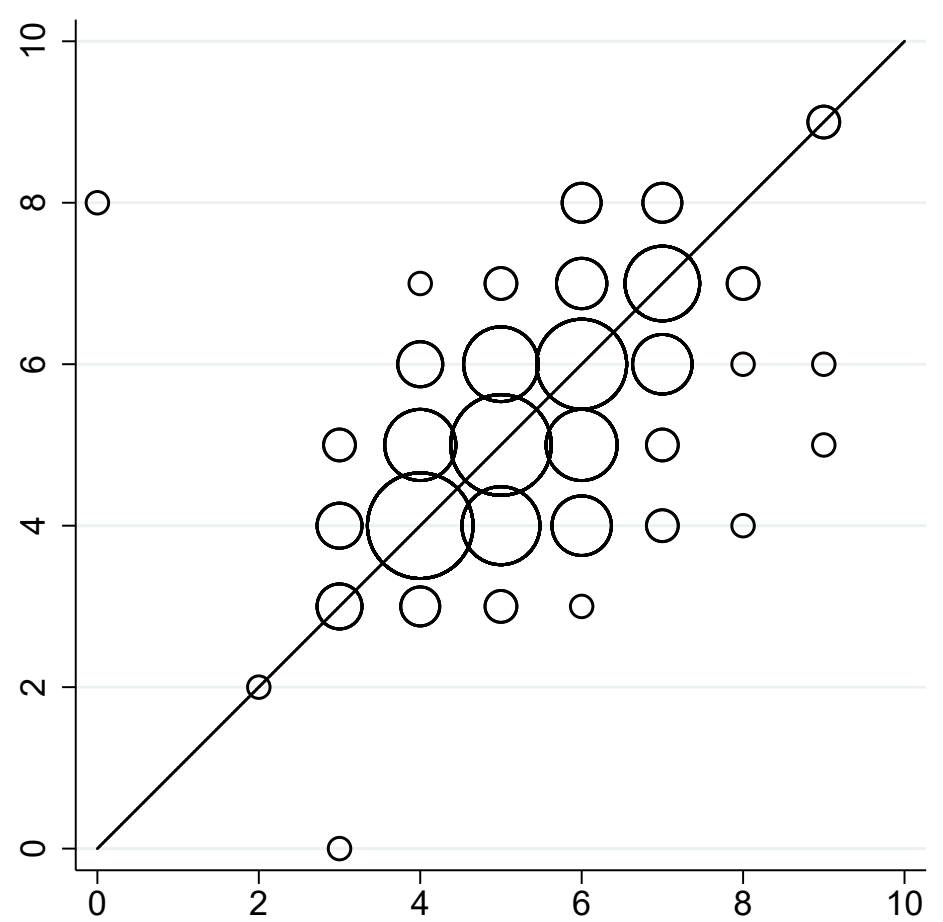

Figure 1: Scatter plot of the number of safe choices in the two repetitions of HL 2002

Finally, as in all MPL tasks, it is not uncommon that some "inconsistent" subjects switch back from the risky to the safe option. Engel and Kirchakamp (2019) use the information included in these multiple switches to obtain information about the noise. We will follow an alternative path for three reasons. First, the number of multiple switches is only small in the datasets we use (under $10 \%$ in the original HL experiment and under $5 \%$ in our ESSEC replication). Second, most subjects seem to consider the whole task as one unique choice, choosing the row from which they want to switch to the risky option, and not as a multiple-choice task (Hey et al. (2009)). Third, the two repetitions of the task provide us with enough information to determine the lower bound of the measurement error in this risk-aversion elicitation task. 


\section{Estimating the variance of the measurement error}

\section{Maximum-Likelihood Assumptions}

We wish to estimate the mean and variance of our variable of interest $x^{*}$ and the variance of the measurement error $\epsilon_{i}$ using standard maximum-likelihood procedures. To do so we use the following notation and simplifying assumptions:

- Variable of interest $x^{*} \sim \mathcal{N}\left(m, \sigma_{x}{ }^{2}\right)$ truncated over [0,10] (with a density function of f).

- Measurement error for observation $i \in\{1,2\}, \epsilon_{i} \sim \mathcal{N}\left(0, \sigma_{\epsilon}^{2}\right)^{6}$ (with a distribution function of $\Phi)$.

- $\epsilon_{1}, \epsilon_{2}$ and $x^{*}$ are all independent of each other.

- We observe $x_{1}=\left\lfloor x^{*}+\epsilon_{1}\right\rfloor$ and $x_{2}=\left\lfloor x^{*}+\epsilon_{2}\right\rfloor^{\text {日 }}$.

- The unknown parameters are $\theta=\left\{m, \sigma_{x}, \sigma_{\epsilon}\right\}$.

Figure 2 presents the number of safe choices in the test and retest conditions in Holt and Laury (2002). Their shapes suggest that normality is a plausible assumption.
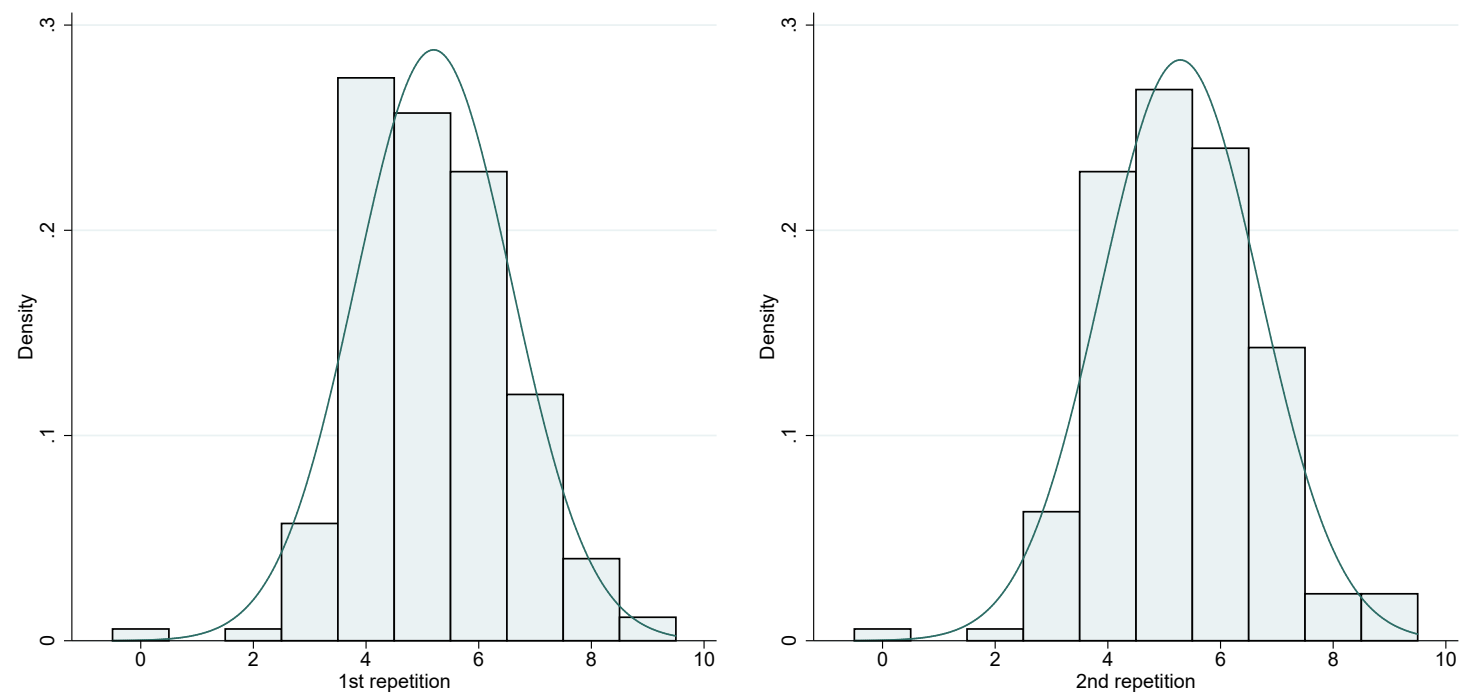

Figure 2: Number of safe choices in the two repetitions of HL 2002

\footnotetext{
${ }^{6}$ We could assume that $\epsilon_{1}$ and $\epsilon_{2}$ are drawn from normal distributions with different variances.

${ }^{7}$ In extreme cases we can have $x^{*}+\epsilon<0\left(\operatorname{resp} x^{*}+\epsilon \geq 11\right)$ : in this case we observe $x=0(\operatorname{resp} x=10)$ and not $\left\lfloor x^{*}+\epsilon\right\rfloor$. This is not an issue here as we never find that $x^{*}+\epsilon<0$ or $>11$ in our simulations.
} 


\section{Likelihood function}

Under our assumptions, we can determine for any $\theta$ the likelihood function that shows how likely it is that the parameter $\theta$ is the correct one given the assumed model and the observations.

$$
\begin{aligned}
L(\theta) & =\prod_{i=1}^{N} P\left(x_{1}=x_{1 i} \bigcap x_{2}=x_{2 i} \mid \theta\right) \\
& =\prod_{i=1}^{N} \int_{0}^{10} P\left(x_{1}=x_{1 i} \bigcap x_{2}=x_{2 i} \mid x^{*}=u, \theta\right) f(u \mid \theta) d u \\
& =\prod_{i=1}^{N} \int_{0}^{10} P\left(x_{1 i} \leq u+\epsilon_{1}<x_{1 i}+1 \bigcap x_{2 i} \leq u+\epsilon_{2}<x_{2 i}+1 \mid x^{*}=u, \theta\right) f(u \mid \theta) d u \\
& =\prod_{i=1}^{N} \int_{0}^{10}\left(\Phi\left(x_{1 i}+1-u\right)-\Phi\left(x_{1 i}-u\right)\right)\left(\Phi\left(x_{2 i}+1-u\right)-\Phi\left(x_{2 i}-u\right)\right) f(u \mid \theta) d u
\end{aligned}
$$

\section{Calibrations}

We maximize the log-likelihood function to obtain the maximum-likelihood estimator: $\theta^{M}=\left\{m^{M}, \sigma_{x}^{M}, \sigma_{\epsilon}^{M}\right\}$.

Table 2: Maximum-Likelihood Estimates

\begin{tabular}{ccc}
\hline \hline$m^{M}$ & $\sigma_{x}^{M}$ & $\sigma_{\epsilon}^{M}$ \\
\hline 5.743 & 1.028 & 0.899 \\
$(0.093)$ & $(0.082)$ & $(0.052)$ \\
\hline \hline
\end{tabular}

The data we collected in a replication study carried out at the ESSEC Experimental Lab in 2017 produce similar-sized estimates: see Appendix A.

\section{Simulations}

\section{Fictive outcomes and assumptions}

Now that we have estimated the variance of the measurement error, as well as the mean and variance of the variable of interest $x^{*}$, we can use a simple linear stochastic model to simulate an outcome variable $y^{*}$ in order to evaluate the size of the measurement-error problem in simple OLS regressions, with particular emphasis on the value, significance and variance of the estimated coefficient. The simulations are carried out using the following 
assumptions:

$$
\begin{array}{llll}
\text { - } y^{*}=\alpha+\beta x^{*}+u & x^{*} \sim \mathcal{N}\left(m^{M}, \sigma_{x}^{M} ;[0,10]\right) & u \sim \mathcal{N}\left(0, \sigma_{u}{ }^{2}\right) & X^{*} \Perp u \\
\text { - } x=\left\lfloor x^{*}+\epsilon\right\rfloor \quad \text { with } \epsilon \sim \mathcal{N}\left(0, \sigma_{\epsilon}^{2}\right) & X^{*} \Perp \epsilon & \epsilon \Perp u \\
\text { - } \sigma_{u}^{2}=1 & &
\end{array}
$$

Under these assumptions and for the $\beta$ we consider, we have $\operatorname{Corr}\left(y^{*}, x^{*}\right) \simeq \beta$.

\section{Obviously Related Instrumental Variable}

Gillen et al. (2019) argue convincingly that the test/retest design and the duplication of a noisy measure can help to correct attenuation bias and improve the significance of the estimated coefficients.

In a first step, they show that simple IV regressions (2SLS) using $x_{1}$ as an instrument for $x_{2}$ (or the reverse) already improve the quality of the estimation.

To make the best use of all available information, and because there is no reason to prefer $x_{1}$ to instrument $x_{2}$, or $x_{2}$ to instrument $x_{1}$, they combine the two IV regressions in one convex combination, via a method they called Obviously Related Instrumental Variables. This requires that the errors in the $1^{\text {st }}$ and $2^{\text {nd }}$ measures be independent.

We will implement both the IV and the ORIV methods, which will allow us to emphasize the benefits of the latter. For ORIV, we estimate the stacked model:

$$
\begin{gathered}
\qquad\left(\begin{array}{l}
y^{*} \\
y^{*}
\end{array}\right)=\left(\begin{array}{l}
\alpha_{1} \\
\alpha_{2}
\end{array}\right)+\beta\left(\begin{array}{l}
x_{1} \\
x_{2}
\end{array}\right)+u \\
\text { instrumenting }\left(\begin{array}{l}
x_{1} \\
x_{2}
\end{array}\right) \quad \text { by } W=\left(\begin{array}{ll}
x_{2} & 0_{N} \\
0_{N} & x_{1}
\end{array}\right)
\end{gathered}
$$

Table 3 displays the coefficient estimates from 100000 simulated experiments with 100 subjects, a sample size that is relatively common in laboratory experiments. We use in the simulation five "actual" coefficients $\beta=(0.15,0.20,0.25,0.30,0.35)$, of relatively small size, as these can be more sensitive to the measurement-error problem. The table shows the estimated mean, variances and frequencies of the significance of these estimators (at three error levels). We stack the estimates by the method of generating the latent variable (the true one, discretization, noise, and discretization and noise), and the estimation of the coefficient when the latent variable is noisy and truncated (IV and ORIV). 
To help intuition, Figure 3 presents the distribution of the estimates for $\beta=0.25$ in the six relevant simulations (the true variable, discretization, noise only, discretization and noise, simple IV and ORIV) for $\mathrm{N}=100$; Table 4 displays the analogous estimates for a sample size of 200 .

In Appendix B we provide coefficient estimates for "large" samples (up to N=1000), which appear much less frequently in laboratory experiments, but are common when using internet data collection through specialized platforms, or in some field studies. 
Table 3: Simulations: Simple OLS and IV with N=100 (100 000 simulations)

\begin{tabular}{|c|c|c|c|c|c|c|}
\hline & $\beta$ & 0.15 & 0.2 & 0.25 & 0.3 & 0.35 \\
\hline \multirow[t]{5}{*}{$x^{*}$} & Mean $\hat{\beta}$ & 0.1505 & 0.1998 & 0.2497 & 0.2999 & 0.3505 \\
\hline & (St Dev) & 0.0986 & 0.0985 & 0.099 & 0.099 & 0.0987 \\
\hline & Sig 0.1 & $45.19 \%$ & $64.69 \%$ & $80.91 \%$ & $91.40 \%$ & $96.79 \%$ \\
\hline & Sig 0.05 & $32.88 \%$ & $52.41 \%$ & $71.03 \%$ & $85.26 \%$ & $93.70 \%$ \\
\hline & Sig 0.01 & $14.34 \%$ & $28.42 \%$ & $46.99 \%$ & $66.17 \%$ & $81.90 \%$ \\
\hline \multirow{5}{*}{$\left\lfloor x^{*}\right\rfloor$} & Mean $\hat{\beta}$ & 0.1395 & 0.185 & 0.2314 & 0.2779 & 0.3248 \\
\hline & (St Dev) & 0.095 & 0.0951 & 0.0955 & 0.0958 & 0.0954 \\
\hline & Sig 0.1 & $42.94 \%$ & $61.59 \%$ & $78.10 \%$ & $89.26 \%$ & $95.65 \%$ \\
\hline & Sig 0.05 & $30.94 \%$ & $49.12 \%$ & $67.64 \%$ & $82.30 \%$ & $91.77 \%$ \\
\hline & Sig 0.01 & $13.18 \%$ & $25.83 \%$ & $43.12 \%$ & $61.79 \%$ & $77.89 \%$ \\
\hline \multirow[t]{5}{*}{$x^{*}+\epsilon$} & Mean $\hat{\beta}$ & 0.0855 & 0.1131 & 0.1415 & 0.1699 & 0.1987 \\
\hline & (St Dev) & 0.0749 & 0.0748 & 0.0753 & 0.0761 & 0.0765 \\
\hline & Sig 0.1 & $30.87 \%$ & $44.71 \%$ & $59.18 \%$ & $72.18 \%$ & $82.63 \%$ \\
\hline & Sig 0.05 & $20.62 \%$ & $32.53 \%$ & $46.75 \%$ & $60.70 \%$ & $73.34 \%$ \\
\hline & Sig 0.01 & $7.50 \%$ & $14.02 \%$ & $23.84 \%$ & $36.12 \%$ & $50.11 \%$ \\
\hline \multirow{5}{*}{$\left\lfloor x^{*}+\epsilon\right\rfloor$} & Mean $\hat{\beta}$ & 0.0818 & 0.1083 & 0.1355 & 0.1627 & 0.1902 \\
\hline & (St Dev) & 0.0732 & 0.0732 & 0.0737 & 0.0745 & 0.075 \\
\hline & Sig 0.1 & $30.09 \%$ & $43.24 \%$ & $57.63 \%$ & $70.61 \%$ & $81.02 \%$ \\
\hline & Sig 0.05 & $19.93 \%$ & $31.28 \%$ & $45.02 \%$ & $58.84 \%$ & $71.28 \%$ \\
\hline & Sig 0.01 & $7.11 \%$ & $13.35 \%$ & $22.64 \%$ & $34.32 \%$ & $47.66 \%$ \\
\hline \multirow[t]{5}{*}{ IV } & Mean $\hat{\beta}$ & 0.1533 & 0.2028 & 0.2538 & 0.3057 & 0.3563 \\
\hline & (St Dev) & 0.1413 & 0.1427 & 0.1439 & 0.146 & 0.1478 \\
\hline & Sig 0.1 & $28.69 \%$ & $42.24 \%$ & $56.78 \%$ & $70.14 \%$ & $81.03 \%$ \\
\hline & Sig 0.05 & $18.10 \%$ & $29.42 \%$ & $43.16 \%$ & $57.65 \%$ & $70.61 \%$ \\
\hline & Sig 0.01 & $5.14 \%$ & $10.45 \%$ & $19.08 \%$ & $30.44 \%$ & $43.78 \%$ \\
\hline \multirow[t]{5}{*}{ ORIV } & Mean $\hat{\beta}$ & 0.1521 & 0.2013 & 0.2518 & 0.3031 & 0.3536 \\
\hline & (St Dev) & 0.1218 & 0.1227 & 0.124 & 0.126 & 0.1273 \\
\hline & Sig 0.1 & $36.52 \%$ & $52.27 \%$ & $67.80 \%$ & $80.51 \%$ & $89.32 \%$ \\
\hline & Sig 0.05 & $25.27 \%$ & $39.92 \%$ & $55.66 \%$ & $70.52 \%$ & $82.12 \%$ \\
\hline & Sig 0.01 & $10.17 \%$ & $18.94 \%$ & $31.75 \%$ & $46.48 \%$ & $61.58 \%$ \\
\hline
\end{tabular}

The first column indicates the variable or the estimation method used in the univariate OLS regression. The first variable is the true $x^{*}$, the second the discretization of the true variable, the third considers the effect of noise, the fourth combines noise and discretization. For the IV estimations, the discrete noisy measure $\left\lfloor x_{1}^{*}+\epsilon\right\rfloor$ is instrumented by $\left\lfloor x_{2}^{*}+\epsilon\right\rfloor$. For the ORIV estimations the stack model uses $\left\lfloor x_{j}^{*}+\epsilon\right\rfloor$ for $j \in\{1,2\}$. The last five columns indicate the average value, standard deviation and significance of $\beta$ for 100000 simulations. For instance the ORIV cell for Sig 0.1 and $\beta=0.15$ is $36.52 \%$, so that the estimated $\beta$ using ORIV is significant in $36.52 \%$ of the 100000 regressions at the $10 \%$ level when the true $\beta$ is 0.15 . 
Table 4: Simulations: Simple OLS and IV with N=200 (100 000 simulations)

\begin{tabular}{|c|c|c|c|c|c|c|}
\hline & $\beta$ & 0.15 & 0.2 & 0.25 & 0.3 & 0.35 \\
\hline \multirow[t]{5}{*}{$x^{*}$} & Mean $\hat{\beta}$ & 0.15 & 0.1999 & 0.2501 & 0.3 & 0.3502 \\
\hline & (St Dev) & 0.0695 & 0.0692 & 0.0692 & 0.0695 & 0.0691 \\
\hline & Sig 0.1 & $69.72 \%$ & $89.26 \%$ & $97.32 \%$ & $99.58 \%$ & $99.95 \%$ \\
\hline & Sig 0.05 & $57.98 \%$ & $82.02 \%$ & $94.66 \%$ & $98.92 \%$ & $99.85 \%$ \\
\hline & Sig 0.01 & $33.72 \%$ & $61.36 \%$ & $84.14 \%$ & $95.50 \%$ & $99.11 \%$ \\
\hline \multirow[t]{5}{*}{$\left\lfloor x^{*}\right\rfloor$} & Mean $\hat{\beta}$ & 0.139 & 0.1853 & 0.2318 & 0.278 & 0.3245 \\
\hline & (St Dev) & 0.0669 & 0.0666 & 0.0668 & 0.067 & 0.0668 \\
\hline & Sig 0.1 & $66.91 \%$ & $86.98 \%$ & $96.35 \%$ & $99.30 \%$ & $99.90 \%$ \\
\hline & Sig 0.05 & $54.86 \%$ & $78.99 \%$ & $93.00 \%$ & $98.41 \%$ & $99.72 \%$ \\
\hline & Sig 0.01 & $30.83 \%$ & $56.98 \%$ & $80.64 \%$ & $93.63 \%$ & $98.51 \%$ \\
\hline \multirow[t]{5}{*}{$x^{*}+\epsilon$} & Mean $\hat{\beta}$ & 0.085 & 0.1131 & 0.1415 & 0.1702 & 0.1984 \\
\hline & (St Dev) & 0.0526 & 0.0524 & 0.053 & 0.0535 & 0.0538 \\
\hline & Sig 0.1 & $48.91 \%$ & $69.35 \%$ & $84.70 \%$ & $93.64 \%$ & $97.80 \%$ \\
\hline & Sig 0.05 & $36.78 \%$ & $57.29 \%$ & $76.02 \%$ & $88.73 \%$ & $95.59 \%$ \\
\hline & Sig 0.01 & $16.94 \%$ & $33.08 \%$ & $53.38 \%$ & $72.42 \%$ & $86.18 \%$ \\
\hline \multirow[t]{5}{*}{$\left\lfloor x^{*}+\epsilon\right\rfloor$} & Mean $\hat{\beta}$ & 0.0813 & 0.1083 & 0.1355 & 0.1629 & 0.1899 \\
\hline & (St Dev) & 0.0515 & 0.0513 & 0.0519 & 0.0524 & 0.0528 \\
\hline & Sig 0.1 & $47.58 \%$ & $67.61 \%$ & $83.20 \%$ & $92.67 \%$ & $97.33 \%$ \\
\hline & Sig 0.05 & $35.35 \%$ & $55.45 \%$ & $74.18 \%$ & $87.30 \%$ & $94.73 \%$ \\
\hline & Sig 0.01 & $16.04 \%$ & $31.49 \%$ & $51.15 \%$ & $69.91 \%$ & $84.25 \%$ \\
\hline \multirow[t]{5}{*}{ IV } & Mean $\hat{\beta}$ & 0.1512 & 0.2018 & 0.2524 & 0.3026 & 0.3531 \\
\hline & (St Dev) & 0.097 & 0.0974 & 0.0986 & 0.1 & 0.1014 \\
\hline & Sig 0.1 & $47.30 \%$ & $67.63 \%$ & $83.38 \%$ & $92.93 \%$ & $97.48 \%$ \\
\hline & Sig 0.05 & $34.58 \%$ & $55.21 \%$ & $74.10 \%$ & $87.47 \%$ & $94.87 \%$ \\
\hline & Sig 0.01 & $14.53 \%$ & $29.60 \%$ & $49.88 \%$ & $69.18 \%$ & $84.00 \%$ \\
\hline \multirow[t]{5}{*}{ ORIV } & Mean $\hat{\beta}$ & 0.1506 & 0.2008 & 0.2511 & 0.3015 & 0.3517 \\
\hline & (St Dev) & 0.0845 & 0.0847 & 0.0859 & 0.0871 & 0.0881 \\
\hline & Sig 0.1 & $56.87 \%$ & $77.65 \%$ & $90.81 \%$ & $97.16 \%$ & $99.28 \%$ \\
\hline & Sig 0.05 & $44.24 \%$ & $67.12 \%$ & $84.60 \%$ & $94.22 \%$ & $98.38 \%$ \\
\hline & Sig 0.01 & $22.34 \%$ & $42.88 \%$ & $65.44 \%$ & $82.94 \%$ & $93.33 \%$ \\
\hline
\end{tabular}

The first column indicates the variable or estimation method used in the univariate OLS regression. The first variable is the true $x^{*}$, the second the discretization of the true variable, the third considers the effect of noise, the fourth combines noise and discretization. For the IV estimations, the discrete noisy measure $\left\lfloor x_{1}^{*}+\epsilon\right\rfloor$ is instrumented by $\left\lfloor x_{2}^{*}+\epsilon\right\rfloor$. For the ORIV estimations the stack model uses $\left\lfloor x_{j}^{*}+\epsilon\right\rfloor$ for $j \in\{1,2\}$. The last five columns indicate the average value, standard deviation and significance of $\beta$ for 100000 simulations. For instance the ORIV cell for Sig 0.1 and $\beta=0.15$ is $56.87 \%$, so that the estimated $\beta$ using ORIV method is significant in $56.87 \%$ of the 100 000 regressions at the $10 \%$ level when the true $\beta$ is 0.15 . 


\section{Discussion of the results}

(a) In line with theory, these simulations confirm that measurement error attenuates the coefficient of the variable of interest in univariate OLS regression: the "true" coefficient is approximately divided by 2 . Increasing the size of the sample does not remove this bias, but does improve the significance of the coefficients.

(b) In small samples $(\mathrm{N}=100)$, measurement errors substantially affect the significance of the coefficients. For instance, with $\beta=0.25$ the coefficient is significant at the $5 \%$ level only $46.75 \%$ of the time. This helps explain why the coefficients of "meaningful" variables by any theoretical standard are often insignificant in experimental research .

(c) The use of a discrete measure of a continuous variable of interest such as risk-aversion does not appear to be a major problem. As we can see from the simulation tables, this transformation only slightly reinforces the downward bias in the coefficients.

(d) For small samples ( $\mathrm{N}=100)$ simple IV and ORIV estimations do not fully remove the measurement problem: while the bias is virtually eliminated, the frequency of insignificant coefficients is still very high (at 43 and 55 per cent, respectively, at the 5 per cent significance level).

(e) In larger samples $(\mathrm{N}=200)$ the ORIV estimator performs relatively well. Not only is the bias virtually eliminated, but significance is also improved (in particular as compared to the IV estimates). The ORIV coefficients are slightly upward-biased due to the discrete transformation of the observations. See Appendix B for an comparative performance analysis of IV and ORIV in large samples $(\mathrm{N}=1000)$.

The frequency curves in Figure 3 depict the distribution of the estimated coefficients (for beta $=0.25$, and $\mathrm{N}=100$ ). These show that: (1) the main source of the bias is the measurement error; (2) the discrete transformation of the continuous variable of interest does not much shift the distribution; and (3) the ORIV method eliminates the bias but produces a higher variance. 


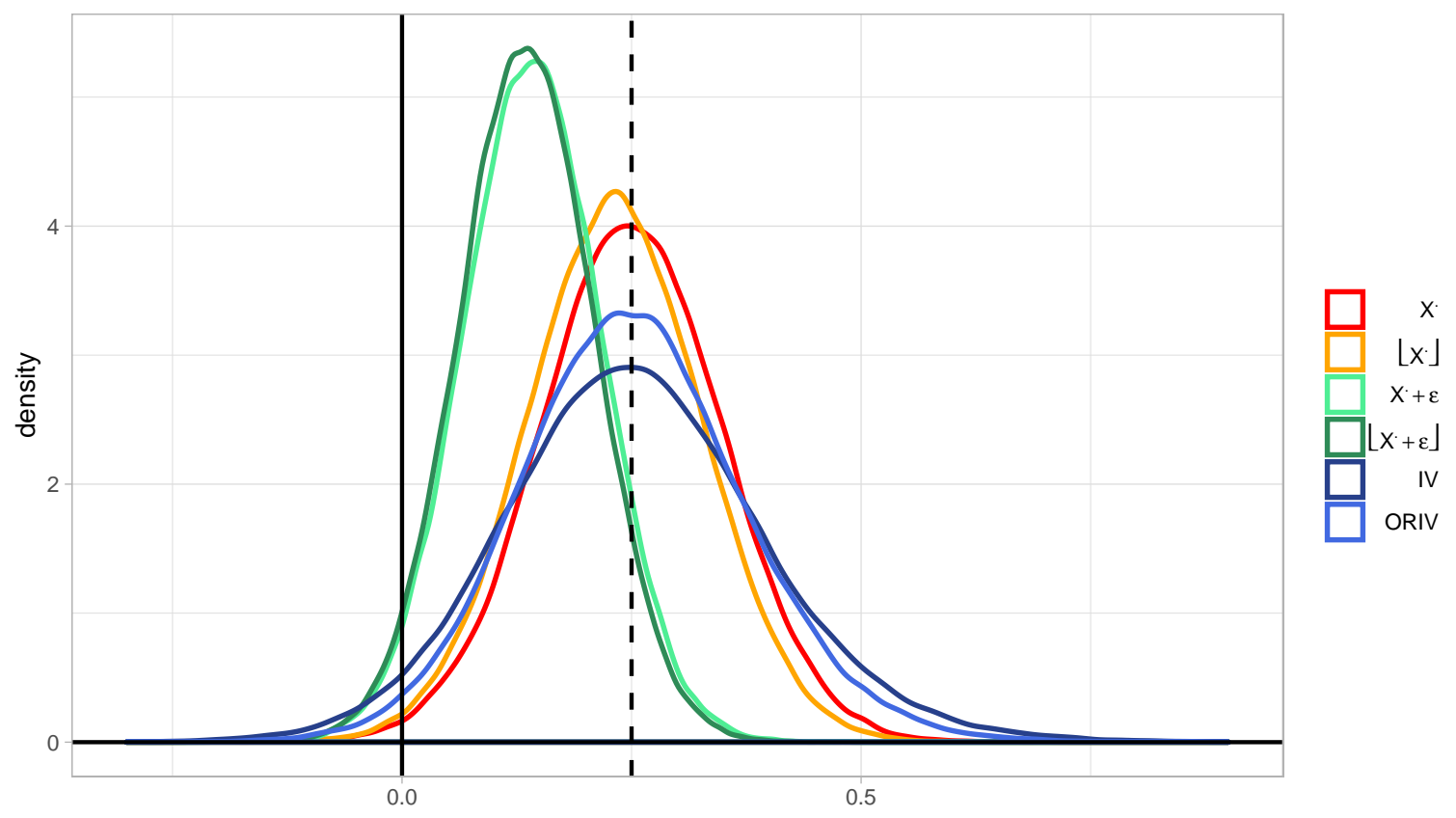

Figure 3: The distribution of the estimators for $\beta=0.25$ and $\mathrm{N}=100$

\section{Conclusion}

By cutting the estimated coefficients in half and substantially reducing their significance, the problem of measurement error appears too large to be ignored. For instance, the proportion of regressions in which the coefficient of risk aversion appear significant is roughly divided by two for $\mathrm{N}=200$ for a significance level of 0.01 . As a consequence, the external validity of measures of risk-aversion is greatly undermined. While we here focus on the Holt-Laury method - the most popular method - there is no reason to believe that different elicitation methods would not lead to similar results.

Our results of course depend on simplifying assumptions that are made throughout the text. While many of these are quite standard (such as assuming that the variable of interest and the error terms are normally-distributed) others can be criticized. In particular, we assumed that the errors in the two repeated tasks are orthogonal. We furthermore ruled out the possibility of an individual switching back and forth in HL-like tasks, even though this behavior is often observed in practice. However, we do not feel that alternative assumptions would have dramatically changed our conclusions: intra-subject variability is too large to be ignored as a cause of measurement error.

Our confidence in the robustness of our results derives from the large variability of within- 
subject measures in test/retest data, which is now well-documented. In particular, the task used to elicit risk-aversion, as well as the delay between the test and the retest, have little influence on the importance of intra-subject variability, which remains large in all instances. 8

A second lesson from our work here relates to sample size. The problems arise when the sample is of the size typical in experimental economics. Most of the significance issues disappear with $N=1000$. Since it may be too costly to systematically increase sample sizes up to this value, we suggest the use of IV or ORIV estimation, which corrects most problems for $N$ over 200. Smaller samples are definitely prone to measurement errors, and the results regarding the significance of the risk-aversion coefficient should be interpreted cautiously. This requires eliciting two measures of the variable of interest (risk-aversion in our case), which is probably less costly than doubling or tripling the sample size.

Within the framework of these simplifying assumptions, our study should be seen as a first attempt to use test/retest data to determine the size of the measurement error in probably the most popular risk-aversion elicitation task to date. It also provides new evidence supporting the use of the ORIV method.

\section{References}

Attanasi, G., N. Georgantzís, V. Rotondi, and D. Vigani (2018). Lottery-and survey-based risk attitudes linked through a multichoice elicitation task. Theory and Decision 84(3), $341-372$.

Bardsley, N., R. Cubitt, G. Loomes, P. Moffat, C. Starmer, and R. Sugden (2010). Experimental Economics: Rethinking the Rules. Princeton University Press.

Charness, G., T. Garcia, T. Offerman, and M. Villeval (2019). Do measures of risk attitude in the laboratory predict behavior under risk in and outside of the laboratory? GATE Working Paper No. 1921.

Chuang, Y. and L. Schechter (2015). Stability of experimental and survey measures of risk, time, and social preferences: A review and some new results. Journal of Development Economics 117, 151-170.

Crosetto, P. and A. Filippin (2016). A theoretical and experimental appraisal of four risk elicitation methods. Experimental Economics 19(3), 613-641.

\footnotetext{
${ }^{8}$ See Chuang and Schechter (2015). Revnaud and Couture (2012), Crosetto and Filippin (2016), Schildberg-Hörisch (2018) and Mata et al. (2018) for a meta-analysis.
} 
Engel, C. and O. Kirchakamp (2019). How to deal with inconsistent choices on multiple price lists. Journal of Economic Behavior and Organization 160, 138-157.

Frederick, S. (2005, December). Cognitive reflection and decision making. Journal of Economic Perspectives 19(4), 25-42.

Gillen, B., E. Snowberg, and L. Yariv (2019). Experimenting with measurement error: Techniques with applications to the Caltech cohort study. Journal of Political Economy 127(4), $1826-1863$.

Hey, J. D., A. Morone, and U. Schmidt (2009). Noise and bias in eliciting preferences. Journal of Risk and Uncertainty 39(3), 213-235.

Holt, C. A. and S. K. Laury (2002). Risk aversion and incentive effects. American Economic Review 92(5), 1644-1655.

Jacobson, S. and R. Petrie (2009). Learning from mistakes: What do inconsistent choices over risk tell us? Journal of Risk and Uncertainty 38(2), 143-158.

Mata, R., R. Frey, D. Richter, J. Schupp, and R. Hertwig (2018). Risk preference: A view from psychology. Journal of Economic Perspectives 32(2), 155-72.

O'Donoghue, T. and J. Somerville (2018, May). Modeling risk aversion in economics. Journal of Economic Perspectives 32(2), 91-114.

Reynaud, A. and S. Couture (2012). Stability of risk preference measures: results from a field experiment on french farmers. Theory and Decision 73(2), 203-221.

Schildberg-Hörisch, H. (2018). Are risk preferences stable? Journal of Economic Perspectives 32(2), 135-54.

Zhou, W. and J. Hey (2018). Context matters. Experimental Economics 21(4), 723-756.

\section{Appendix A. A replication of $\mathrm{HL}$}

We replicated the HL test/retest procedure in 2019, with a total of 60 participants in three experimental sessions organized at the ESSEC Experimental Lab (France). Subjects made their decisions on a computer screen and could not establish eye contact with one another; the instructions and data collection were computerized. 
The experiment included a first HL risk-elicitation task (Table 1), two attention-diversion tasks (lasting for approximately 10 minutes) and a second HL risk-elicitation task, identical to the first.

The first diversion was the CRT (cognitive-reflection task) introduced by Frederick (2005). The second was a simple real-effort task (counting 7's) that subjects had to carry out for four minutes. These tasks were not incentivized.

Subjects also indicated their age, gender and major track in their Secondary education.

The payoffs for the session are based on the results from one randomly-selected risk task. The session lasted approximately 20 minutes and participants earned on average 7 Euros.

Note that the frequency of multiple switches in these data is very low, at under 5 percent.
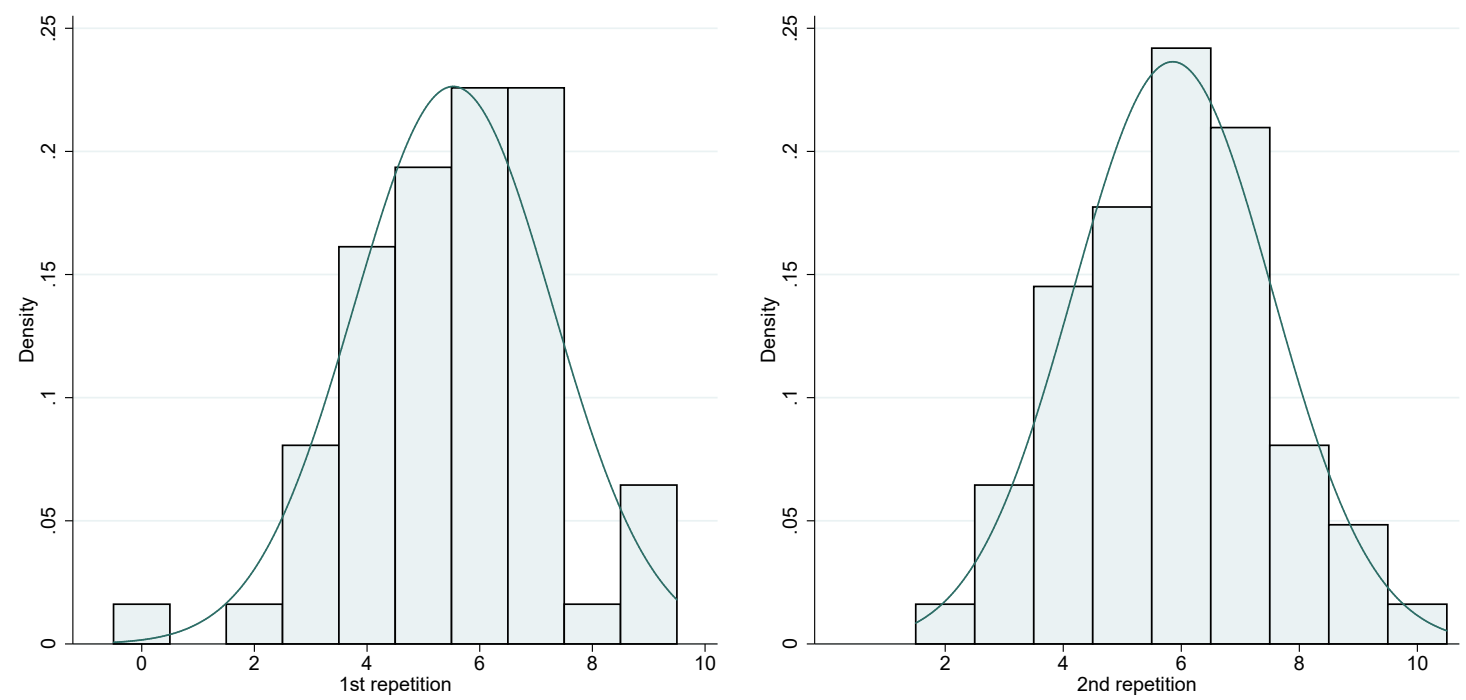

Figure 4: The number of safe choices in the two repetitions of the HL task in the ESSEC replication study

Table 5: Maximum-Likelihood Estimates for the ESSEC students

\begin{tabular}{ccc}
\hline \hline$m^{M}$ & $\sigma_{x}^{M}$ & $\sigma_{\epsilon}^{M}$ \\
\hline 6.205 & 1.319 & 1.092 \\
$(0.199)$ & $(0.182)$ & $(0.103)$ \\
\hline \hline
\end{tabular}

\section{Appendix B. Simulations for "large" samples}

In this Appendix we provide estimates for "large" samples: $N=300, N=500$ and $N=1000$ (over 10000 simulations). 
Table 6: Simulations: Simple OLS and IV with N=300 (10 000 simulations)

\begin{tabular}{|c|c|c|c|c|c|c|}
\hline & $\beta$ & 0.15 & 0.2 & 0.25 & 0.3 & 0.35 \\
\hline \multirow[t]{5}{*}{$x^{*}$} & Mean $\hat{\beta}$ & 0.1495 & 0.1998 & 0.2499 & 0.3003 & 0.3499 \\
\hline & (St Dev) & 0.0564 & 0.0569 & 0.0563 & 0.0564 & 0.0569 \\
\hline & Sig 0.1 & $84.31 \%$ & $96.96 \%$ & $99.71 \%$ & $100.00 \%$ & $100.00 \%$ \\
\hline & Sig 0.05 & $75.19 \%$ & $93.99 \%$ & $99.20 \%$ & $99.95 \%$ & $100.00 \%$ \\
\hline & Sig 0.01 & $52.27 \%$ & $82.86 \%$ & $96.53 \%$ & $99.54 \%$ & $99.97 \%$ \\
\hline \multirow{5}{*}{$\left\lfloor x^{*}\right\rfloor$} & Mean $\hat{\beta}$ & 0.1385 & 0.1853 & 0.2318 & 0.2782 & 0.3242 \\
\hline & (St Dev) & 0.0543 & 0.0547 & 0.0545 & 0.0547 & 0.055 \\
\hline & Sig 0.1 & $81.49 \%$ & $95.82 \%$ & $99.42 \%$ & $99.97 \%$ & $100.00 \%$ \\
\hline & Sig 0.05 & $71.97 \%$ & $92.08 \%$ & $98.70 \%$ & $99.89 \%$ & $100.00 \%$ \\
\hline & Sig 0.01 & $48.28 \%$ & $79.29 \%$ & $94.85 \%$ & $99.24 \%$ & $99.95 \%$ \\
\hline \multirow[t]{5}{*}{$x^{*}+\epsilon$} & Mean $\hat{\beta}$ & 0.0848 & 0.1129 & 0.142 & 0.1701 & 0.1979 \\
\hline & (St Dev) & 0.0424 & 0.0432 & 0.0427 & 0.0435 & 0.0436 \\
\hline & Sig 0.1 & $63.56 \%$ & $83.87 \%$ & $95.04 \%$ & $98.76 \%$ & $99.73 \%$ \\
\hline & Sig 0.05 & $51.34 \%$ & $74.54 \%$ & $90.80 \%$ & $97.29 \%$ & $99.42 \%$ \\
\hline & Sig 0.01 & $27.74 \%$ & $51.99 \%$ & $75.59 \%$ & $90.28 \%$ & $97.32 \%$ \\
\hline \multirow[t]{5}{*}{$\left\lfloor x^{*}+\epsilon\right\rfloor$} & Mean $\hat{\beta}$ & 0.0813 & 0.1081 & 0.1358 & 0.1628 & 0.1895 \\
\hline & (St Dev) & 0.0416 & 0.0423 & 0.0417 & 0.0427 & 0.0428 \\
\hline & Sig 0.1 & $62.00 \%$ & $82.38 \%$ & $94.35 \%$ & $98.37 \%$ & $99.63 \%$ \\
\hline & Sig 0.05 & $49.69 \%$ & $72.44 \%$ & $89.23 \%$ & $96.68 \%$ & $99.24 \%$ \\
\hline & Sig 0.01 & $25.92 \%$ & $49.49 \%$ & $73.50 \%$ & $88.82 \%$ & $96.53 \%$ \\
\hline \multirow[t]{5}{*}{ IV } & Mean $\hat{\beta}$ & 0.1507 & 0.2006 & 0.2512 & 0.3014 & 0.3518 \\
\hline & (St Dev) & 0.0777 & 0.0794 & 0.0795 & 0.0806 & 0.0814 \\
\hline & Sig 0.1 & $61.47 \%$ & $82.43 \%$ & $94.13 \%$ & $98.46 \%$ & $99.75 \%$ \\
\hline & Sig 0.05 & $48.32 \%$ & $72.85 \%$ & $89.58 \%$ & $96.65 \%$ & $99.23 \%$ \\
\hline & Sig 0.01 & $25.12 \%$ & $48.69 \%$ & $73.01 \%$ & $88.88 \%$ & $96.48 \%$ \\
\hline \multirow[t]{5}{*}{ ORIV } & Mean $\hat{\beta}$ & 0.1503 & 0.2001 & 0.2508 & 0.3011 & 0.3508 \\
\hline & (St Dev) & 0.0679 & 0.0697 & 0.0689 & 0.0705 & 0.0715 \\
\hline & Sig 0.1 & $72.08 \%$ & $89.90 \%$ & $97.77 \%$ & $99.64 \%$ & $99.99 \%$ \\
\hline & Sig 0.05 & $60.35 \%$ & $83.17 \%$ & $95.75 \%$ & $99.07 \%$ & $99.90 \%$ \\
\hline & Sig 0.01 & $35.81 \%$ & $63.94 \%$ & $86.06 \%$ & $96.03 \%$ & $99.28 \%$ \\
\hline
\end{tabular}

The first column indicates the variable or estimation method used in the univariate OLS regression. The first variable is the true $x^{*}$, the second the discretization of the true variable, the third considers the effect of noise, the fourth combines noise and discretization. For the IV estimations, the discrete noisy measure $\left\lfloor x_{1}^{*}+\epsilon\right\rfloor$ is instrumented by $\left\lfloor x_{2}^{*}+\epsilon\right\rfloor$. For the ORIV estimations the stack model uses $\left\lfloor x_{j}^{*}+\epsilon\right\rfloor$ for $j \in\{1,2\}$. The last five columns indicate the average value, standard deviation and significance of $\beta$ for 10000 simulations. For instance the ORIV cell for Sig 0.1 and $\beta=0.15$ is $72.08 \%$, so that the estimated $\beta$ using ORIV method is significant in $72.08 \%$ of the 10 000 regressions at the $10 \%$ level when the true $\beta$ is 0.15 . 
Table 7: Simulation: Simple OLS and IV with N=500 (10 000 simulations)

\begin{tabular}{|c|c|c|c|c|c|c|}
\hline & $\beta$ & 0.15 & 0.2 & 0.25 & 0.3 & 0.35 \\
\hline \multirow[t]{5}{*}{$x^{*}$} & Mean $\hat{\beta}$ & 0.1506 & 0.1999 & 0.2504 & 0.3003 & 0.3498 \\
\hline & (St Dev) & 0.0435 & 0.0438 & 0.0438 & 0.0438 & 0.0441 \\
\hline & Sig 0.1 & $96.46 \%$ & $99.76 \%$ & $99.99 \%$ & $100.00 \%$ & $100.00 \%$ \\
\hline & Sig 0.05 & $93.06 \%$ & $99.51 \%$ & $99.97 \%$ & $100.00 \%$ & $100.00 \%$ \\
\hline & Sig 0.01 & $80.32 \%$ & $97.60 \%$ & $99.90 \%$ & $100.00 \%$ & $100.00 \%$ \\
\hline \multirow{5}{*}{$\left\lfloor x^{*}\right\rfloor$} & Mean $\hat{\beta}$ & 0.1394 & 0.1854 & 0.2321 & 0.2784 & 0.3242 \\
\hline & (St Dev) & 0.0421 & 0.0423 & 0.0425 & 0.0423 & 0.0425 \\
\hline & Sig 0.1 & $95.16 \%$ & $99.62 \%$ & $99.98 \%$ & $100.00 \%$ & $100.00 \%$ \\
\hline & Sig 0.05 & $90.96 \%$ & $99.22 \%$ & $99.95 \%$ & $100.00 \%$ & $100.00 \%$ \\
\hline & Sig 0.01 & $76.32 \%$ & $96.39 \%$ & $99.79 \%$ & $100.00 \%$ & $100.00 \%$ \\
\hline \multirow[t]{5}{*}{$x^{*}+\epsilon$} & Mean $\hat{\beta}$ & 0.0852 & 0.1134 & 0.1419 & 0.1704 & 0.198 \\
\hline & (St Dev) & 0.033 & 0.0331 & 0.0332 & 0.0337 & 0.0338 \\
\hline & Sig 0.1 & $82.56 \%$ & $96.21 \%$ & $99.46 \%$ & $99.98 \%$ & $100.00 \%$ \\
\hline & Sig 0.05 & $72.80 \%$ & $92.63 \%$ & $98.74 \%$ & $99.89 \%$ & $100.00 \%$ \\
\hline & Sig 0.01 & $50.01 \%$ & $79.99 \%$ & $95.10 \%$ & $99.29 \%$ & $99.94 \%$ \\
\hline \multirow[t]{5}{*}{$\left\lfloor x^{*}+\epsilon\right\rfloor$} & Mean $\hat{\beta}$ & 0.0814 & 0.1086 & 0.1358 & 0.1631 & 0.1894 \\
\hline & (St Dev) & 0.0323 & 0.0324 & 0.0325 & 0.033 & 0.0331 \\
\hline & Sig 0.1 & $80.73 \%$ & $95.43 \%$ & $99.34 \%$ & $99.98 \%$ & $100.00 \%$ \\
\hline & Sig 0.05 & $71.03 \%$ & $91.49 \%$ & $98.52 \%$ & $99.87 \%$ & $99.99 \%$ \\
\hline & Sig 0.01 & $47.48 \%$ & $77.86 \%$ & $94.08 \%$ & $99.06 \%$ & $99.89 \%$ \\
\hline \multirow[t]{5}{*}{ IV } & Mean $\hat{\beta}$ & 0.1513 & 0.2003 & 0.2508 & 0.3017 & 0.3505 \\
\hline & (St Dev) & 0.0607 & 0.0608 & 0.0614 & 0.0622 & 0.0639 \\
\hline & Sig 0.1 & $80.87 \%$ & $95.76 \%$ & $99.40 \%$ & $99.92 \%$ & $100.00 \%$ \\
\hline & Sig 0.05 & $71.45 \%$ & $91.74 \%$ & $98.73 \%$ & $99.82 \%$ & $100.00 \%$ \\
\hline & Sig 0.01 & $47.63 \%$ & $77.17 \%$ & $94.30 \%$ & $99.13 \%$ & $99.94 \%$ \\
\hline \multirow[t]{5}{*}{ ORIV } & Mean $\hat{\beta}$ & 0.1506 & 0.2003 & 0.2506 & 0.3013 & 0.3499 \\
\hline & (St Dev) & 0.0528 & 0.0534 & 0.0536 & 0.0543 & 0.0556 \\
\hline & Sig 0.1 & $89.45 \%$ & $98.29 \%$ & $99.86 \%$ & $100.00 \%$ & $100.00 \%$ \\
\hline & Sig 0.05 & $82.11 \%$ & $96.84 \%$ & $99.70 \%$ & $99.99 \%$ & $100.00 \%$ \\
\hline & Sig 0.01 & $61.75 \%$ & $89.13 \%$ & $98.42 \%$ & $99.89 \%$ & $100.00 \%$ \\
\hline
\end{tabular}

The first column indicates the variable or estimation method used in the univariate OLS regression. The first variable is the true $x^{*}$, the second the discretization of the true variable, the third considers the effect of noise, the fourth combines noise and discretization. For the IV estimations, the discrete noisy measure $\left\lfloor x_{1}^{*}+\epsilon\right\rfloor$ is instrumented by $\left\lfloor x_{2}^{*}+\epsilon\right\rfloor$. For the ORIV estimations the stack model uses $\left\lfloor x_{j}^{*}+\epsilon\right\rfloor$ for $j \in\{1,2\}$. The last five columns indicate the average value, standard deviation and significance of $\beta$ for 10000 simulations. For instance the ORIV cell for Sig 0.1 and $\beta=0.15$ is $89.45 \%$, so that the estimated $\beta$ using ORIV method is significant in $89.45 \%$ of the 10 000 regressions at the $10 \%$ level when the true $\beta$ is 0.15 . 
Table 8: Simulation: Simple OLS and IV with N=1000 (10 000 simulations)

\begin{tabular}{|c|c|c|c|c|c|c|}
\hline & $\beta$ & 0.15 & 0.2 & 0.25 & 0.3 & 0.35 \\
\hline \multirow[t]{5}{*}{$x^{*}$} & Mean $\hat{\beta}$ & 0.1501 & 0.2001 & 0.2497 & 0.3004 & 0.3497 \\
\hline & (St Dev) & 0.0305 & 0.0313 & 0.0308 & 0.0305 & 0.0308 \\
\hline & Sig 0.1 & $99.97 \%$ & $100.00 \%$ & $100.00 \%$ & $100.00 \%$ & $100.00 \%$ \\
\hline & Sig 0.05 & $99.88 \%$ & $99.99 \%$ & $100.00 \%$ & $100.00 \%$ & $100.00 \%$ \\
\hline & Sig 0.01 & $99.11 \%$ & $99.99 \%$ & $100.00 \%$ & $100.00 \%$ & $100.00 \%$ \\
\hline \multirow[t]{5}{*}{$\left\lfloor x^{*}\right\rfloor$} & Mean $\hat{\beta}$ & 0.1392 & 0.1854 & 0.2316 & 0.2784 & 0.3242 \\
\hline & (St Dev) & 0.0293 & 0.0301 & 0.0295 & 0.0294 & 0.0296 \\
\hline & Sig 0.1 & $99.92 \%$ & $99.99 \%$ & $100.00 \%$ & $100.00 \%$ & $100.00 \%$ \\
\hline & Sig 0.05 & $99.76 \%$ & $99.98 \%$ & $100.00 \%$ & $100.00 \%$ & $100.00 \%$ \\
\hline & Sig 0.01 & $98.59 \%$ & $99.96 \%$ & $100.00 \%$ & $100.00 \%$ & $100.00 \%$ \\
\hline \multirow[t]{5}{*}{$x^{*}+\epsilon$} & Mean $\hat{\beta}$ & 0.0852 & 0.1136 & 0.1416 & 0.1702 & 0.1982 \\
\hline & (St Dev) & 0.0231 & 0.0236 & 0.0236 & 0.0233 & 0.0239 \\
\hline & Sig 0.1 & $97.97 \%$ & $99.91 \%$ & $100.00 \%$ & $100.00 \%$ & $100.00 \%$ \\
\hline & Sig 0.05 & $95.67 \%$ & $99.82 \%$ & $100.00 \%$ & $100.00 \%$ & $100.00 \%$ \\
\hline & Sig 0.01 & $85.42 \%$ & $98.61 \%$ & $99.94 \%$ & $100.00 \%$ & $100.00 \%$ \\
\hline \multirow{5}{*}{$\left\lfloor x^{*}+\epsilon\right\rfloor$} & Mean $\hat{\beta}$ & 0.0815 & 0.1086 & 0.1355 & 0.163 & 0.1896 \\
\hline & (St Dev) & 0.0227 & 0.023 & 0.023 & 0.0229 & 0.0234 \\
\hline & Sig 0.1 & $97.56 \%$ & $99.89 \%$ & $100.00 \%$ & $100.00 \%$ & $100.00 \%$ \\
\hline & Sig 0.05 & $95.04 \%$ & $99.65 \%$ & $100.00 \%$ & $100.00 \%$ & $100.00 \%$ \\
\hline & Sig 0.01 & $83.69 \%$ & $98.32 \%$ & $99.91 \%$ & $100.00 \%$ & $100.00 \%$ \\
\hline \multirow[t]{5}{*}{ IV } & Mean $\hat{\beta}$ & 0.1505 & 0.2006 & 0.2502 & 0.3009 & 0.3499 \\
\hline & (St Dev) & 0.0422 & 0.0435 & 0.0433 & 0.0436 & 0.0441 \\
\hline & Sig 0.1 & $97.20 \%$ & $99.85 \%$ & $100.00 \%$ & $100.00 \%$ & $100.00 \%$ \\
\hline & Sig 0.05 & $94.53 \%$ & $99.61 \%$ & $100.00 \%$ & $100.00 \%$ & $100.00 \%$ \\
\hline & Sig 0.01 & $83.84 \%$ & $98.26 \%$ & $99.97 \%$ & $100.00 \%$ & $100.00 \%$ \\
\hline \multirow[t]{5}{*}{ ORIV } & Mean $\hat{\beta}$ & 0.1504 & 0.2005 & 0.2501 & 0.3006 & 0.3498 \\
\hline & (St Dev) & 0.037 & 0.0379 & 0.0378 & 0.0379 & 0.0388 \\
\hline & Sig 0.1 & $99.27 \%$ & $99.96 \%$ & $100.00 \%$ & $100.00 \%$ & $100.00 \%$ \\
\hline & Sig 0.05 & $98.34 \%$ & $99.93 \%$ & $100.00 \%$ & $100.00 \%$ & $100.00 \%$ \\
\hline & Sig 0.01 & $93.27 \%$ & $99.67 \%$ & $99.99 \%$ & $100.00 \%$ & $100.00 \%$ \\
\hline
\end{tabular}

The first column indicates the variable or estimation method used in the univariate OLS regression. The first variable is the true $x^{*}$, the second the discretization of the true variable, the third considers the effect of noise, the fourth combines noise and discretization. For the IV estimations, the discrete noisy measure $\left\lfloor x_{1}^{*}+\epsilon\right\rfloor$ is instrumented by $\left\lfloor x_{2}^{*}+\epsilon\right\rfloor$. For the ORIV estimations the stack model uses $\left\lfloor x_{j}^{*}+\epsilon\right\rfloor$ for $j \in\{1,2\}$. The last five columns indicate the average value, standard deviation and significance of $\beta$ for 10000 simulations. For instance the IV cell for Sig 0.1 and $\beta=0.15$ is $97.20 \% \mathrm{~s}$, so that the estimated $\beta$ using ORIV method is significant in $97.20 \%$ of the 10000 regressions at the $10 \%$ level when the true $\beta$ is 0.15 . 


\section{ESSEC}

BUSINESS SCHOOL

ESSEC Business School

3 avenue Bernard-Hirsch

CS 50105 Cergy

95021 Cergy-Pontoise Cedex

France

Tel. +33 (0)134433000

www.essec.edu

\section{ESSEC Executive Education}

CNIT BP 230

92053 Paris-La Défense

France

Tel. +33 (0)1 46924900

www.executive-education.essec.edu

\section{ESSEC Asia-Pacific}

5 Nepal Park

Singapore 139408

Tel. +65 68849780

ESSEC | CPE Registration number 200511927D

Period of registration: 30 June 2017 - 29 June 2023

Committee of Private Education (CPE) is part of SkillsFuture Singapore (SSG)

\section{ESSEC Africa}

Plage des Nations - Golf City

Route de Kênitra - Sidi Bouknadel (Rabat-Salê)

Morocco

Tel. +212 (0)5 37824000

www.essec.edu 